Author Posting. (c) 'Copyright Holder', 2009.

This is the author's pre-proof version of the work. It is posted here by permission of

'Copyright Holder' for personal use, not for redistribution.

The definitive version was published in The Service Industries Journal, 29(10) 2009.

doi:10.1080/02642060903038879 (http://dx.doi.org/10.1080/02642060903038879)

\title{
Critical hospitality management research
}

Dr Peter Lugosi a

Dr Paul Lynch b

Professor Alison Morrison c

a School of Services Management, Bournemouth University, Poole, Dorset, BH12 5BB, plugosi@bournemouth.ac.uk

b Strathclyde Business School, University of Strathclyde, Glasgow, G4 OLG, paul.lynch@strath.ac.uk

c Strathclyde Business School, University of Strathclyde, Glasgow, G4 0LG,

alison.j.morrison@strath.ac.uk

\section{Abstract}

This paper discusses the development of critical hospitality management research (CHMR) and explores key issues that such approaches raise. The paper is split into two parts. The first reviews contemporary writings that reflect the changing nature of hospitality management research and accounts for the emergence of a critical tradition. The second part identifies eight areas which are central concerns for the future development of CHMR: criticality, ethics and advocacy, scale, claims of legitimacy and research quality, representation, audience, affiliation, institutions and institutional contexts, and the relationship between management research and pedagogy. Associated questions and challenges are surfaced and conclusions drawn.

Key words: hospitality, critical, research, management Introduction

Hospitality management research has evolved significantly over the past four decades. Several commentators have highlighted the growing methodological and 
conceptual complexity of emerging work (Pizam, 2008; Rivera and Upchurch, 2008), while others have pointed to the broadening scope and theoretical diversity of contemporary research (Jones, 2004; Lashley, 2008a; Lashley et al., 2007a; Morrison, 2002). The development of diverse approaches to hospitality management research has led several commentators to distinguish between traditional and emerging forms (Jones, 2004; Lashley, 2008a, 2008b; Lashley et al., 2007b). Advocates of different approaches are sometimes conceived as being members of disparate academic 'tribes' (Becher and Trowler, 2001), with incompatible norms, methods and approaches (Jones and Lockwood, 2008, Slattery, 1985, 2002, 2003). However, a growing body of work has demonstrated how alternative conceptual and methodological approaches can enhance hospitality management research (Hemmington, 2007; Lashley, 2008a; Lugosi, 2008; Robinson and Lynch, 2007; Morrison and O'Gorman, 2008). This paper builds on and contributes to this body of work by identifying how emergent, critical approaches, which encompass an array of methods, theories and philosophies (Wilson, Harris and Small, 2008), can develop a new agenda for hospitality management research.

Thus, the paper has two aims: to outline the basis for the development of a critical agenda for hospitality management research; and to identify the key questions and challenges that such a critical approach raises for academics. This, in turn, helps to scope out the direction of future research and shape the principles that underpin it. Consequently, the paper is structured into two parts. The first reviews contemporary writings that reflect the changing nature of hospitality management academia and accounts for the emergence of a critical approach. The second part identifies eight areas which are central concerns for the future development of critical hospitality management research (CHMR): criticality, ethics and advocacy, scale, claims of legitimacy and research quality, representation, audience, affiliation, institutions and institutional contexts, and finally, the relationship between management research and pedagogy. Associated questions and challenges are surfaced and conclusions drawn.

\section{The development of a critical approach}

In social sciences, debates about the limitations of value-neutral research, reliant on scientific measures and realist or positivistic epistemologies has led to the development of alternative qualitative approaches (Denzin and Lincoln, 2005a; 2005b). These have evolved into broader critical ethical and political movements that have transformed the nature of social scientific inquiry. Management studies and tourism research are going through similar processes of transition, where existing orthodoxies about purpose and methodologies are being questioned (for example, Alvesson and Willmott, 1992, 2004; Grey and Willmott, 2005a; Fournier and Grey, 2000; see also Ateljevic et al., 2007 for changes in tourism research). By way of background, critical management studies (CMS) is a broad conceptual church (Grey and Willmott, 2005), and Thompson (2004) associates CMS with critical theory, critical realism and postmodernism. CMS acknowledges a range of perspectives as well as a variety of stakeholders in addition to management (Grey and Willmott, 2005b). Fournier and Grey (2000) suggest three key inter-related concepts that underpin CMS: de-naturalization, the questioning of normative hierarchies; anti-performativity, challenging the idea that social relations should be entirely instrumental; and reflexivity, which disputes positivist research assumptions and/or a masquerade of neutrality and universality. In the CMS 
'project', it is axiomatic to question the underlying premises of knowledge production, that is, assumptions, commonsense thinking and disciplinary paraphernalia that assures the authority of the production. Grey and Willmott (2005b) argue that CMS follows a basically constructivist ontology where the field is manufactured in the minds of the field researchers rather than by what is 'out there'. Reflexivity becomes significant not just to take account of author influence but also regarding the processes taking place during knowledge generation. There is an interest in hierarchies, conceptualized as exercises of power, which is focused on how they are produced, legitimised, and the consequences that arise for what is held to be knowledge. More importantly, a significant feature of CMS is the willingness to be self-critical. For example, Thompson (2004) has criticised CMS on three grounds: a tendency to critique but without resolving anything; an undervaluing of quantitative research; and an 'extreme epistemic suspicion' (369).

Kuhn (1996) suggests that the evolution of scientific theory emerges not from the straightforward accumulation of facts, but from a set of changing intellectual circumstances and possibilities. Emerging subject areas and disciplines evolve through disagreements about the appropriateness and limitations of existing methods and methodologies, which provoke the development of alternative ones. Arguably, one can see such a process occurring currently in higher education. University business faculties are being encouraged to adopt more social scientific orientations, and the content of Masters of Business Administration degrees is being critiqued as unsuited to demands of modern day management (Ivory et al., 2008). This latter academic weakness is perceived as contributing in some way to the current international credit crunch because graduates are weak in critical thinking and follow too slavishly the precepts of positivism and neo-classical economics; insights from other areas are required, including history, literature and art (Caulkin, 2008).

The adoption of Kuhn's (1996) model allows for the charting of hospitality subject development. It provides a 'window' through which the academic insiders and outsiders can observe the manner in which factions within the community have intellectually challenged received assumptions, beliefs, and engaged in reflection, questioning the prevalent paradigm of the time. Jones (2004) and Lugosi (2009) argue that engaging in a process of critical reflection attests to the advancement that hospitality has made. Morrison and O'Gorman (2005: 455) stress this point in arguing that this process is significant contributing: 'valuable texture and structure to a maturing academic field, and is essential for progress'.

The development of critical approaches to hospitality management research was inevitable, and it is possible to identify a number of factors that have led to this. Hospitality academia does not operate in isolation. The labour pool of hospitality researchers is arguably more diverse than hitherto, and the numbers of people with social scientific training entering hospitality management departments has increased; existing hospitality management academics are exposed to debates concerning critical approaches and they are increasingly engaging in discussions about the state of hospitality research (cf. Lashley and Morrison, 2000; Lashley et al. 2007a; Lugosi, 2008; Morrison and Lynch, 2007).

Debates surrounding the nature of hospitality management academia and the role of social scientific approaches have repeatedly emerged over the past three decades. Academics have questioned the theorisation of hospitality (Nailon, 1982), the historical 
and social nature of hospitality, including its potential to shape practice (Burgess, 1982; Hepple et al., 1990; King, 1995) as well as the role of social science in hospitality management education (cf., Lennon and Wood, 1992; Slattery, 1983; Wood, 1983, 1988). These works reveal a desire among hospitality academics to think critically about what they are attempting to study. They also highlight the need to critique the approaches used to research and teach hospitality.

Hospitality management research tends to be dominated by quantitative research and positivist epistemologies (cf. Crawford-Welch and McCleary, 1992; Hemming et al., 2005; Jones, 1998; Taylor and Edgar, 1996, 1999). However, more recently this has been countered by Tribe (2006) who proposes that tourism and hospitality studies have moved beyond the strait-jacketed fascination with positivistic research to embrace more reflexive and critical paths of enquiry. Debates about the focus of hospitality research, the fundamental assumptions that underpin it, and the approaches utilised have been reignited in recent years. Researchers have critiqued existing positivist methodologies (Botterill, 2000), while proposing and evaluating alternative phenomenological and interpretative ones (Lynch, 2005; Sandiford and Seymour, 2007). Authors have reconsidered the scope and conceptual depth of hospitality research and have attempted to engage with a broader range of disciplines (cf. Lashley, 2008a; Lashley and Morrison, 2000; Lashley et al., 2007a; Lugosi, 2007a, 2007b, 2008, 2010; Lynch, 2005; Morrison, 2002). Finally, academics have also reconsidered the nature of teaching on hospitality management courses and the need to develop a broader, critical approach to its study (Morrison and O'Mahony, 2003; Morrison and O'Gorman, 2008). These emerging debates, coupled with those taking place in management studies, social science and tourism help to identify the essential features of a critical tradition. These are summarised below and in Figure 1, which positions this emerging approach in relation to contemporary hospitality management and the broader hospitality studies research agenda exemplified by Lashley (2008a) and Lashley et al. (2007b). It proposes that hospitality research may be characterised as following three orientations: hospitality management, critical hospitality management, and hospitality studies. In this representation, hospitality management research and hospitality studies research partly overlap, and is depicted thus in order to capture their 'symbiotic relationship' (Morrison and O'Gorman, 2008), and the conceptual spaces they create for critical hospitality management research as well as for their intellectually independent spaces. 


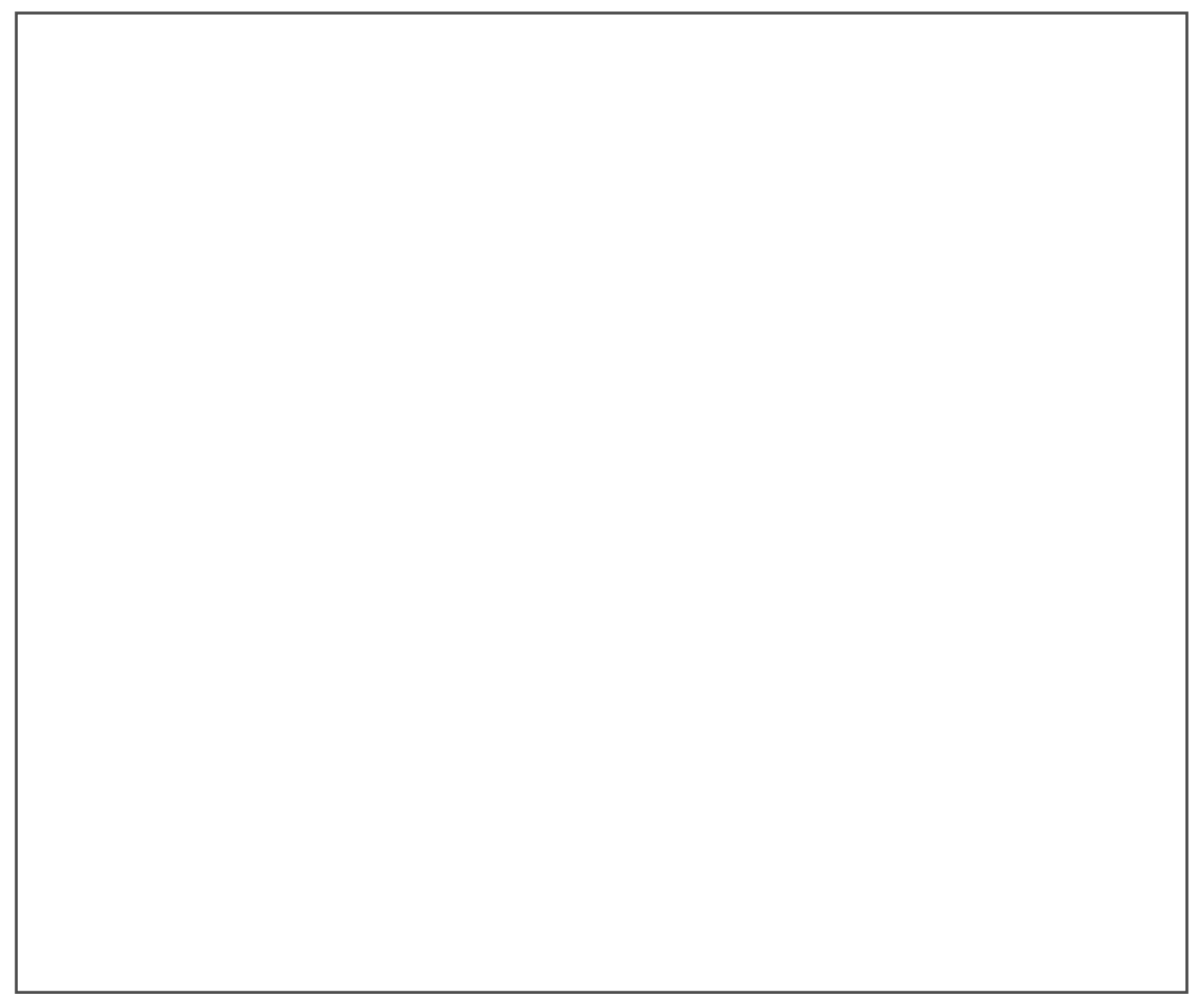

Key features associated with CHMR as depicted in Figure 1 include:

- self-reflexive insofar as its practitioners are willing to engage in a process of selfevaluation and criticism;

- theoretically and conceptually rich, while avoiding reductionism or simplistic claims about truth;

- while it recognises critiques of the tyranny of relevance (Taylor and Edgar, 1996) it seeks to find new opportunities to apply emerging ideas to management research, practice and education;

- pluralistic in terms of embracing a wide range of methods and epistemologies;

- problematisation of quantitative methods, including the realist and positivist epistemologies underpinning them - although this should not mean that it must abandon them altogether, and researchers may seek ways to integrate different, supposedly incompatible approaches;

- experimental and willing to embrace risk, marginality and partiality; and

- ethical, conscious of power and the problematic nature of research relationships as well as issues of representation, ownership of knowledge and the consequences of research (see for example Lugosi, 2006).

In summary, hospitality management research that has dominated the hospitality subject to date is conceived of as essentially pro-business, preoccupied with managerial practice and issues of industry importance (Lashley, 2000; Slattery, 2002), and essentially positivist or realist in orientation (Botterill, 2000). Researchers typically adopt 
statistical research methods giving rise to the creation of truth claims (Crawford-Welch and McCleary, 1992; Jones, 1998), and, relative to critical hospitality management and hospitality studies research, are conservative - supporting normative organisational management perspectives, values and assumptions (Lashley, 2000; Taylor and Edgar, 1996; 1999). Researchers are supported by management oriented collegiate networks.

Hospitality studies research has been a constant but understated dimension of the hospitality subject (Lashley, 2008a). It is broadly concerned with exploring the social, cultural, political and ethical dimensions of hospitality and is theory-oriented, seeking to build and interlink with wider theoretical arguments and propositions for the advancement of knowledge for its own sake (Lashley et al., 2007a). Moreover, hospitality studies has attempted to use hospitality to understand a wide range of social processes and has thus sought to advance other disciplinary knowledge (cf., Bell, 2007; Germann Molz and Gibson, 2007; Lugosi and Lugosi, 2008). Highly liberal in its approach, researchers often adhere to phenomenological or constructivist ontologies adopting experimental research methods associated with the more recent historical moments of qualitative research where researcher reflexivity is stressed in order to foreground the subjective process in the construction of knowledge (for example, Germann Molz and Gibson, 2007; Lashley et al. 2007a; Lugosi, 2006; Lynch, 2005). Multiple disciplinary perspectives are brought to bear and researchers engage with a complex set of collegiate networks.

Critical hospitality management research is formed from the areas of overlap between the two traditions, emanating from the tensions between, on the one hand, a desire to challenge some of the orthodoxies and normative assumptions of hospitality management research and, on the other hand, a concern with enhancing hospitality management research by employing the strengths of social scientific approaches (cf., Hemmington, 2007; Lugosi, 2007b, 2008; Wood, 2007). Thus, in this conceptual meetingground, critical hospitality management research's concern is with theory informed practice, with dual advocacy of management and social scientific orientations. Researchers may draw upon a mix of qualitative and quantitative techniques and are willing to embrace pluralistic and experimental research methods. In relation to their object of study, researchers are ethically aware and reflexive in terms of their influence in the process of creating knowledge. Reflecting their positioning in the academic community, critical researchers draw upon wide collegiate networks that include but extend beyond those involved in the existing hospitality management research community.

Figure 1 is a helpful conceptual framework here for argument-building purposes. It is likely that the description of the salient characteristics of the hospitality research approaches, and their ensuing ontological, epistemological and methodological stances, is broadly recognisable. However, as with any representational device it is problematic in that it implicitly suggests clearer delineations and characteristics than may be the case as well as overlooking the possibility of resistance to such simplistic characterisations. It should also be noted that critical hospitality management research emanates from its own academic cultural context which should not be assumed to mirror that of a broader CMS. Thus, its precise form and development will be grounded within the priorities determined by the hospitality research community.

\section{Questions and challenges for a critical research agenda}


From the foregoing discussion it is possible to identify eight areas, which pose particular questions and intellectual, structural and processual challenges for the development of CHMR. The eight areas emerged from a critical analysis of contemporary debates about knowledge generation (Denzin and Lincoln, 2000; 2005a), management research (Clegg et al., 2006; Fournier and Grey, 2000) as well as debates about research in cognate areas (Franklin and Crang, 2001). The issues raised here draw on recent discussions about the present and future of hospitality management research (cf., Jones and Lockwood, 2008, Lashley, 2008b, Lynch, 2008; Pizam, 2008); and they also reflect on a broader set of factors influencing hospitality management research and education (cf., Airey and Tribe, 2000; Baum, 2008; Hemmington, 2008; Jenkins and Healey, 2005). In short, the following section is concerned with how hospitality management research is conceptualised, how it is produced, applied and how it is evaluated. It also considers the contexts in which management research emerges and the range of stakeholders who are involved in and influenced by its production.

\section{Criticality}

As Ateljevic et al. (2007) argue the notion of criticality is frequently associated with a Marxist or neo-Marxist approach to capitalism and with the establishment of a dissenting group which criticises the status quo but does little to change it or offer reasonable solutions. However, criticality should be thought of partly as an intellectual exercise, which challenges commonly accepted principles, but also as an ideological challenge to initiate change. Criticality here involves a willingness to be critical of the hospitality academy and its existing traditions, as well as the need to remain critical of the practice of hospitality in commercial settings. Indeed, recognition should be given to a range of management approaches from critical pragmatism (Alvesson and Deetz, 2000) to critical theory and critical realism to postmodernism (Thompson, 2004). Further, Thompson (2004) and Clegg et al. (2006) note that CMS in the past has offered radical critiques of management practice, but has not taken enough action to initiate change. The challenge is to apply these insights into research, pedagogy and organisational practice.

\section{Ethics and advocacy}

Following on from the previous point, it is necessary to engage in critical debates about the ethical implications of adopting particular research strategies (see e.g. Lugosi, 2006). More importantly, it is also necessary to question how research engenders enlightened practice, positive change or reinforces existing asymmetric power relations. Ethical management practice in the service sectors and in hospitality organisations is receiving growing attention (cf., Enz, 2002; Rendtorff and Mattsson, 2008; Reynolds, 2000). Ethical decision making is increasingly viewed as an important management skill (Enz, 2002; Kincaid et al., 2008; Reynolds, 2000); student and practitioner engagement with ethics has been examined in a number of studies (Lynn et al., 2007; Stevens, 2001; Upchurch, 1998); and several studies have examined the link between ethical practice and successful business performance (cf., Luria and Yagil, 2008; Rendtorff and Mattsson, 2008; Reynolds, 2000). In developing ethical research the challenge is to 
examine the researcher's stance and how particular interests of stakeholders are best met (Lugosi, 2009); moreover, how researchers can mediate between different stakeholders (see, for example, Rimmington et al., 2006).

\section{Scale, claims of legitimacy and research quality}

Pizam (2008) and Rivera and Upchurch (2008) claimed that the use of complex statistical techniques was evidence that hospitality management research had reached a level of credibility. Although the proposition is laudable, it implies that small scale research and qualitative methods are not considered to be credible. This reflects and reinforces existing discourses of propriety in hospitality management research as well as cultural preferences and traditions regarding research methods. Recognition of qualitative research as a distinctive research method in its own right with differential criteria to determine quality is lacking (Bryman, 2001). Smaller, interpretative studies also have potential to offer important insights into the nature of hospitality management. For example, studies by Marshall (1986), Crang (1994), Fine (1996) and Peacock and Kübler (2001) help to understand the complexity of organisational cultures and service work, and they also reveal the problematic nature of control and power in hospitality organisations. Debates in social science point to alternative criteria for the evaluation of research. Qualitative researchers emphasise notions of subjectivity, positionality, authenticity, aesthetic merit, reflexivity, morality and an overt ethical consciousness, reciprocity, criticality, political engagement, emancipation and polyvocality when discussing the merits of their craft (Lincoln, 1995; Denzin, 2003; Denzin and Lincoln, 2000, 2005a; Richardson, 2000). CHMR will need to challenge criticism directed at credibility and legitimacy. Moreover, in demonstrating further the rich insights provided by alternative methods and methodologies, CHMR has to institutionalise a broader set of quality indicators that include reflexivity and the acknowledgement of the researcher's role in knowledge generation, epistemological transparency, a critical awareness of the ethical dimensions of research and practice, and engagement with a broader set of stakeholder interests. This necessitates rigorous self-criticality in the evaluation of research outputs in terms of scientific value.

\section{Representation and the researcher}

Linked to the production of knowledge is the role of the researcher and also the use of first person narratives. Highly qualitative research methods in hospitality are rare, yet they offer potentially powerful investigatory tools that may open up new avenues and shed new theoretical insights (Lynch, 2005). Such approaches necessitate the researcher acknowledging their role in knowledge production in an open and reflexive manner. In so doing, this should not mean that reflexivity is somehow being privileged over non-reflexive accounts, nor should it lead to narcissistic narratives (Lynch, 2000; Maton, 2003). However, the hospitality researcher is certainly in need of locating themselves in relation to their object of study especially in a context where the purpose of research is highly contested.

\section{Affiliation}

Growing numbers of academics outside hospitality management departments are beginning to engage with the concept of hospitality (Bell, 2007; Germann Molz and Gibson, 2007; Lashley et al., 2007a). This engagement raises serious questions about where hospitality management researchers will find new networks of intellectual camaraderie, and whether emerging hospitality research will feed into broader debates in 
the disciplines of geography, sociology and anthropology, but do little or anything to advance hospitality management scholarship. In particular, one must question the theoretical and philosophical development to date of hospitality management research and consider their future development. There is also the question of current and future interrelationships between tourism and leisure studies, as hospitality is often associated with these subjects. Lynch (2008), for example, has recently questioned whether a closer affiliation with tourism academia is beneficial to future hospitality research. Finally, there is also a need to consider how hospitality can align itself with a broader organisational, human resource or service sector management and whether this will benefit hospitality management research. It is clear that the scope, composition and nature of disciplinary territory that is concerned with hospitality, and affiliations therein, is being remapped. The challenge for critical hospitality management is to demonstrate intellectual contribution, space, place, and tribal affiliation(s) within the new depiction.

\section{Audiencing}

Litteljohn (2004), points to the potential weakening or dilution of hospitality research, which may result from academics publishing in disciplinary focused journals and by shifting emphasis from hospitality specific to more generic management issues. Indeed, it is arguable that hospitality is already an endangered subject as its journals are not rated highly (Harvey, Morris and Kelly, 2008) and appointments and career decisions are being made with regard to them. Such a position is taken by university managers even though examination of how the lists are constructed finds them to be lacking in credibility (Hemmington, 2008). For instance, a foundation stone of the United Kingdom's Association of Business Schools' adopted journal list (Harvey, Morris and Kelly, 2008) is that hospitality and tourism are one and the same subject. Accepting this position permits the authors of the list to legitimise tourism and other non-subject researchers reaching judgements on the quality of the hospitality journals; it also provides a veil of legitimacy for an absence of hospitality expert advisers and an absence of meaningful proactive consultation with the hospitality research community for its views (Hemmington, 2008). This stance is taken despite research indicating that perceptions of research quality differ according to one's subject perspective; simply, hospitality researchers rank hospitality journals higher than tourism researchers and tourism journals less highly and vice versa (McKercher et al., 2006; Sheldon 1990). Howey et al. (1999) report a low incidence of cross-citations among hospitality and tourism research publications; both academic communities are much more inclined to draw on sources from outside either field, approximately $80 \%$ of citations. The distinctiveness of each academic field is evident (Jamal et al., 2008; Stear and Griffin, 1993) and is apparent in the differential institutions and associated apparatus supporting the subjects.

Finally, how is a critical research agenda, with all its intellectual eclecticism served by existing journals? Tribe (2006) and Lugosi (2009) have criticised the existing gatekeepers and institutional forces for perpetuating particular notions of tourism and hospitality research. A more significant presence on editorial boards and reviewer panels of hospitality researchers willing to take a critical approach will help to create a more prominent role for critical hospitality management. As Lugosi (2009) and Morrison and Lynch (2007) argue, it may require the establishment of new journal outlets that can accommodate a broader critical agenda. Thus, within the above context exist many complex audiencing challenges from CHMR, with career progression incentives, ill- 
informed proxies for quality, political and institutional forces, gatekeepers, working counter to the development and dissemination of the field's distinctiveness.

\section{Institutions and institutional contexts}

From the foregoing it can be surmised that an important challenge will be the identity and distinctiveness of hospitality management research within academic institutions. For example, a decision has been made recently to disband the Department of Hospitality and Tourism Management in Strathclyde University with hospitality-related academics being re-located to appropriate cognate groups within the Business School (see Baum, 2008). Commentators have highlighted the challenges faced by social science driven hospitality and leisure researchers in business and management faculties (Lugosi, 2009; Scott and Lugosi, 2005). Researchers' affiliations to different disciplines, communities and institutions can create conflicts of interest and multidisciplinary contribution may be suppressed by the institutional discourses of business schools. Does the absorption of hospitality within business schools endanger hospitality management research by suppressing it in a more mainstream and more established institutional context or will this help to create beneficial new affiliations and critical communities?

\section{Management research and pedagogy}

Finally, it is important to reconsider the relationship between CHMR and pedagogy. Previous exploratory work by Thomas and Harris (2001) highlighted the perceived benefits and challenges associated with research-informed teaching. Certainly there is emphasis on making the link between the two activities more overt (Jenkins, 2004; Jenkins and Healey, 2005). It has already been suggested that applied hospitality management education encompasses ethical, critical and social scientific dimensions (Cole, 2005); the challenge remains to create further curriculum space (Airey and Tribe, 2000) for a critical management approach that complements applied, vocational aspects of hospitality management education. As several commentators have argued (Lashley, 1999; Tribe, 2002; Morrison and O'Mahony, 2003), a critical research agenda feeds into contemporary debates about the need to develop dynamic, reflective practitioners. Botterill (2000: 194) augments this by saying that the status of the field could be increased as: 'Critical social science promises, therefore, to provoke, in this case to raise the status of hospitality and thereby elevate the interests it represents, including, ironically, the hospitality industry'. Thus, equally valued are the research of hospitality and the research of hospitality management as they intersect within a critical analysis framework, for as Morrison and O'Mahony (2003:39) point out for a pedagogical perspective this has the: 'potential to generate new ways of thinking and a wider appreciation of world views'.

\section{Conclusion}

The past two decades has seen numerous debates about the development or maturation of hospitality research (cf. Jones, 1996; 1998; 2004; Litteljohn, 1990; Morrison, 2002; Taylor and Edgar, 1996). Some colleagues are positive about the current state of hospitality research (Pizam, 2003; 2008), while others remain sceptical. Hospitality research did not perform well in the UK Research Assessment Exercise (Jones, 2004, Litteljohn, 2004) and hospitality journals have yet to reach a high level of international recognition in journal rankings (Lynch, 2008). Nevertheless, it is clear that 
hospitality research has evolved and engaging in critical dialogue about its current state and future prospects is further evidence of its ongoing evolution.

The CHMR agenda proposed in this paper reflects and subsequently drives this development process. More importantly, rather than outlining the research agenda for one area of research, for example, consumer behaviour, marketing or operations management, the critical approach discussed here presents the fundamental principles that can underpin research in multiple fields of inquiry. CHMR is not a singular type of research and future studies are likely to reflect one or more features that were highlighted earlier, without conforming to all. Nevertheless, at the core of CHMR is the redefinition of the notion of 'relevance'. Firstly, rather than assume a narrow view of relevance in terms of an audience, that is, to industry, management or even management researchers, CHMR should also show some awareness of relevance to a broader set of stakeholders, including consumers, staff, suppliers, students, academics from diverse disciplines and members of other communities affected by hospitality management research and practice. Secondly, a redefinition of relevance is also concerned with how research may be relevant. More specifically, relevance should no longer be thought of simply in terms of better management practice (for example, lower cost or greater efficiencies) but also relevance in terms of building responsible practice among various stakeholders. Relevance is perhaps best conceived of as involving various degrees of separation from, in this case, management practice. This separation helps to develop the ability to reflect differently on one's work, employing organisation, industry or commercial product; separation may also facilitate a willingness to question normative assumptions and to challenge the status quo. Relevant CHMR may therefore refer to outputs that help to develop moral and intellectual capabilities as well as applicable business techniques and practical competencies.

\section{References}

Airey, D. \& Tribe, J. (2000). Education for hospitality. In C. Lashley and A. Morrison (Eds) In search of hospitality: Theoretical perspectives and debates, (pp. 276-292). Oxford: Butterworth Heinemann.

Alvesson, M. \& Deetz, S. (2000). Doing critical management research. London: Sage.

Alvesson, M. \& Willmott, H. (Eds) (1992). Critical management studies. London: Sage. Alvesson, M. \& Willmott, H. (2003). Studying management critically. London: Sage.

Ateljevic, I., Pritchard, A. \& Morgan, N. (Eds) (2007). The critical turn in tourism studies: Exploring innovative research methodologies. Oxford: Elsevier.

Baum, T. (2008, June 26) Strathclyde University. Message posted to https://listserv.heanet.ie/cgi-bin/wa?A2=ind0806\&L=DIT-TSM-HOSP-IRL\&P=916.

Becher, T. \& Trowler, P. (2001). Academic tribes and territories. 2nd edn Buckingham: Open University Press.

Bell, D. (2007). The hospitable city: Social relations in commercial settings. Progress in Human Geography, 31, 7-22

Botterill, D. (2000). Social scientific ways of knowing hospitality. In C. Lashley and A. Morrison (Eds), In search of hospitality: Theoretical perspectives and debates (pp. 177- 
97). Oxford: Butterworth Heinemann.

Bryman, A. (2001). Social research methods. Oxford: Oxford University Press.

Burgess, J. (1982). Perspectives on gift exchange and hospitable behaviour. International Journal of Hospitality Management 1(1), 49-57.

Caulkin, S. (2008). When it came to the crunch, MBAs didn't help, The Observer, 26 ${ }^{\mathrm{TH}}$ October.

Clegg, S., Kornberger, M., Carter, C. \& Rhodes, C. (2006). For management?. Management Learning, 37(1), 7-27.

Cole, B.L. (2005). Theoretical analysis of "academic credibility" and the hospitality curriculum": The image problem. FIU Hospitality Review, 23(1), 1-6.

Crang, P. (1994). It's showtime: On the workplace geographies of display in a restaurant in southeast England. Environment and Planning D: Society and Space, 12, 675-704.

Crawford-Welch, S. \& McCleary, K. W. (1992). An identification of the subject areas and research techniques used in five hospitality-related journals. International Journal of Hospitality Management, 11(2), 155-167.

Denzin, N. K. \& Lincoln Y. S. (2000). (Eds) Handbook of qualitative research. 2nd edn. Thousand Oaks, CA: Sage.

Denzin, N. K. \& Lincoln Y. S. (2005a). (Eds) Handbook of qualitative research, 3rd edn. Thousand Oaks, CA: Sage.

Denzin, N. K. \&Lincoln, Y. S. (2005b). Introduction: The discipline and practice of qualitative research. In N. K. Denzin and Y. S. Lincoln (Eds) Handbook of qualitative research, 2nd edn (pp. 1-32). Thousand Oaks, CA: Sage.

Denzin, N. K. (2003). Reading and writing performance. Qualitative Research, 3(2), 24368.

Enz, C. (2002). Promoting the human spirit: Key to business success. Cornell Hotel \& Restaurant Administration Quarterly, 43(4), 1.

Fine, G. A. (1996). Kitchens: The culture of restaurant work. Berkeley: University of California Press.

Fournier, V. \& Grey, C. (2000). At the critical moment: Conditions and prospects for critical management studies. Human Relations, 53(1), 7-32.

Franklin, A. \& Crang, M. (2001) The trouble with tourism and travel theory. Tourist Studies, 1(1), 5-22.

Germann-Molz, J. \& Gibson, S. (2007). (Eds) Mobilizing hospitality: The ethics of social relations in a mobile world. Aldershot: Ashgate.

Grey, C. \& Willmott, H. (2005b). Introduction. In C. Grey and H. Willmott (Eds) Critical management studies: A reader (pp. 1-15). Oxford: Oxford University Press.

Grey, C. \& Willmott, H. (2005a). (Eds) Critical management studies: A reader. Oxford: Oxford University Press.

Harvey, C., Morris, H. \& Kelly, A. (eds.) (2008). The Association of Business Schools: Academic Journal Quality Guide - Journals Classified by Field and Quality Rank, www.the-ABS.org.uk accessed 15 April 2008.

Hemmington, N. (2007). From service to experience: Understanding and defining the hospitality business. The Service Industries Journal, 27, 747-755.

Hemmington, N. (2008). Council for Hospitality Management Education (CHME), CHME Executive and Research Committee, Comments on the Association of Business Schools (ABS) 2008 journal quality grading guide with reference to tourism and hospitality 
journals, www.chme.org.uk accessed 25 November 2008.

Henning, K. G., Levy, S. \& Ritchie, J. R. B. (2005). An inquiry into the nature and composition of tourism, leisure and hospitality research. Tourism, 53(3), 187-203.

Hepple, J., Kipps, M. \& Thomson, J. (1990). The concept of hospitality and an evaluation of its applicability to the experience of hospital patients. International Journal of Hospitality Management, 9(4), 305-318.

Howey, R., Savage, K., Verbeeten, M. \& Van Hoof, H. (1999). Tourism and hospitality research journals: Cross-citations among research communities. Tourism Management, 20(1), 133-139.

Ivory, C., Miskell, P., Shipton, H., White, A., Moeslein, K., Neeley, A. (2008). The future of business schools in the UK: Finding a path to success. London: Advanced Institute of Management Research.

Jamal, T., Smith, B. \& Watson, E. (2008). Ranking, rating and scoring of tourism journals: Interdisciplinary challenges and innovations. Tourism Management, 29(1), 66-78.

Jenkins, A. (2004). Designing a curriculum that values a research-based approach to student learning. LINK 9 Spring, 1-4, available at http://www.heacademy.ac.uk/assets/hlst/documents/LINK_Newsletter/Link9.pdf (last accessed 12/11/08).

Jenkins, A. \& Healey, M. (2005). Institutional strategies to link teaching and research. York: Higher Education Academy.

Jones, P. \& Lockwood, A. (2008). Researching hospitality management: It's OK to use the ' $m$ ' word. The Hospitality Review, 10(3), 26-30.

Jones, P. (1998). Editorial. International Journal of Hospitality Management, 17(2), 105110.

Jones, P. (2004). Finding the hospitality industry? Or finding hospitality schools of thought? Journal of Hospitality, Leisure, Sport and Tourism Education, 3(1), 33-45.

Kincaid, C. S., Baloglu, S. \& Corsun, D. (2008). Modelling ethics: The impact of management actions on restaurant workers' ethical optimism. International Journal of Hospitality Management, 27(3), 470-477.

King, C.A. (1995). What is hospitality? International Journal of Hospitality Management, 14(3/4), 219-234.

Kuhn, T. (1996). The structure of scientific revolutions. 3rd edn Chicago: University of Chicago Press.

Lashley, C. (1999.) On making silk purses: Developing reflective practitioners in hospitality management education, International Journal of Contemporary Hospitality Management, 11(4), 180-185.

Lashley, C. (2000). In search of hospitality: Towards a theoretical framework. International Journal of Hospitality Management, 19, 3-15.

Lashley, C. (2008a). Studying hospitality: Insights from social sciences. Scandinavian Journal of Hospitality and Tourism, 8(1), 69-84.

Lashley, C. (2008b). Studying hospitality for commercial success. The Hospitality Review, 10(1), 3-4.

Lashley, C. and Morrison, A. (2000). (Eds) In search of hospitality: Theoretical perspectives and debates. Oxford: Butterworth Heinemann.

Lashley, C., Lynch, P. \& Morrison, A. (2007a). (Eds) Hospitality: A social lens. Oxford: Elsevier. 
Lashley, C., Lynch, P. \& Morrison, A. (2007b). Hospitality: An introduction. In C. Lashley, P. Lynch and A. Morrison (Eds) Hospitality: A social lens (pp. 1-15). Oxford: Elsevier.

Lennon, J.J. \& Wood, R.C. (1992). The teaching of industrial and other sociologies in higher education: The case of hotel and catering management studies, International Journal of Hospitality Management, 11(3), 239-253.

Lincoln, Y. (1995). Emerging criteria for quality in qualitative and interpretative research. Qualitative Inquiry, 1(3), 275-289.

Litteljohn, D. (1990). Hospitality research: Philosophies and progress. In R. Teare, L. Moutinho and N. Morgan (Eds.) Managing and Marketing Services in the 1990s (pp.211227). London: Cassell.

Litteljohn, D. (2004). The UK research assessment exercise 2001: An analysis for hospitality research. International Journal of Hospitality Management, 23(1), 25-38.

Lugosi, P. (2006b). Between overt and covert research: Concealment and revelation in an ethnographic study of commercial hospitality. Qualitative Inquiry, 12(3), 541-561.

Lugosi, P. (2007a). Queer consumption and commercial hospitality: Communitas, myths, and the production of liminoid space. International Journal of Sociology and Social Policy, 27(3/4), 163-174.

Lugosi, P. (2007b). Customer participation in commercial hospitality, International Journal of Culture, Tourism and Hospitality Research, 1(3), 227-236.

Lugosi, P. (2008). Hospitality spaces, hospitable moments: Consumer encounters and affective experiences in commercial settings. Journal of Foodservice, 19(2), 139-149.

Lugosi, P. (2009). Ethnography, ethnographers and hospitality research: Communities, tensions and affiliations. Tourism and Hospitality: Planning and Development, 6(2) (Inpress).

Lugosi, P. (2010) The production of hospitable space: Commercial propositions and consumer co-creation in a bar operation. Space and Culture, 13(4) (In-press)

Lugosi, P. \& Lugosi, K. (2008). Guerrilla hospitality: Urban decay, entrepreneurship and the 'ruin' bars of Budapest. The Hospitality Review, 10(2), 36-44.

Luria, G., \& Yagil, D. (2008). Procedural justice, ethical climate and service outcomes in restaurants. International Journal of Hospitality Management, 27(2), 276-283.

Lynch, M. (2000). Against reflexivity as an academic virtue and source of privileged knowledge. Theory, Culture and Society, 17(3), 26-54.

Lynch, P. (2005). Sociological impressionism in a hospitality context. Annals of Tourism Research, 32(3), 527-548.

Lynch, P. (2008). The positioning of hospitality research, Editorial. The Hospitality Review, 10(1), 3-4.

Lynn, C., Hower, R., \& Combrink, T. (2007). Students' responses to ethical dilemmas. FIU Hospitality Review, 25(2), 1-9.

Marshall, G. (1986). The workplace culture of a licensed restaurant. Theory, Culture and Society, 3(1), 33-47.

Maton, K. (2003). Reflexivity, relationism and research. Space \& Culture, 6(1), 52-65.

McKercher B., Law, R. \& Lam, T. (2006). Rating tourism and hospitality journals. Tourism Management, 27(6), 1235-1252.

Morrison, A. (2002). Hospitality research: A pause for reflection. International Journal of Tourism Research, 4, 161-169. 
Morrison, A. \& Lynch, P. (2007). Hospitality: Subject development. In P. Lynch and D. Sloan (Eds.) The Proceedings of the $16^{\text {th }}$ CHME Research Conference, Oxford: Oxford Brooks University.

Morrison, A. \& O'Gorman, K. (2008). Hospitality studies and hospitality management: A symbiotic relationship. International Journal of Hospitality Management, 27(2), 214-221.

Morrison, A. \& O'Mahony, B. (2003). The liberation of hospitality management education. International Journal of Contemporary Hospitality Management, 15(1), 38-44.

Nailon, P. (1982). Theory in hospitality management. International Journal of Hospitality Management, 1(3), 135-42.

Peacock, M. and Kübler, M. (2001). The failure of 'control' in the hospitality industry, International Journal of Hospitality Management, 20(4), 353-365.

Pizam, A. (2003). Goodbye Rodney Dangerfield, Editorial. International Journal of Hospitality Management, 22(3), 241-242.

Pizam, A. (2008). Advances in hospitality research: From Rodney Dangerfield to Aretha Franklin, Keynote presentation given at the CHME Research Conference. Glasgow: University of Strathclyde.

Rendtorff, J. D. \& Mattsson, J. (2008). Ethical issues in the service industries. The Service Industries Journal, iFirst Article, 1-7.

Reynolds, D. (2000). An exploratory investigation into behaviorally based

success characteristics of foodservice managers. Journal of Hospitality and Tourism Research, 24 (1), 92-103.

Richardson, L. (2000). Evaluating ethnography, Qualitative Inquiry, 6(2), 253-255.

Rimmington, M., Smith, J. C. \& Hawkins, R. (2006). Corporate social responsibility and systainable food procurement. British Food Journal, 108(10), 824-837.

Rivera, M. A. \& Upchurch, R. (2008). The role of research in the hospitality industry: A content analysis of the IJHM between 2000 and 2005, International Journal of Hospitality Management, 27(4), 632-40.

Robinson, M. \& Lynch, P.A. (2007) The power of hospitality: A sociolinguistic analysis. In C. Lashley, P.A. Lynch and A. Morrison (Eds.) Hospitality: A social lens (pp. 141-154) Oxford: Elsevier.

Sandiford, P. \& Seymour, D. (2007). A discussion of qualitative data analysis in hospitality research with examples from an ethnography of English public houses. International Journal of Hospitality Management, 26(3), 724-742.

Scott, J. \& Lugosi, P. (2005). Spreading the net. Anthropology Today, 21(5), 22-23.

Sheldon, P. (1990). Journal Usage in Tourism: Perceptions of Tourism Faculty. Journal of Tourism Studies, 1(1), 42-48.

Slattery, P. (1983). Social science methodology and hospitality management. International Journal of Hospitality Management, 2(1), 9-14.

Slattery, P. (1985). Review of The World of Waiters by Gerald Mars and Michael Nicod, International Journal of Hospitality Management, 4(3), 133.

Slattery, P. (2002). Finding the hospitality industry. Journal of Hospitality, Leisure, Sport and Tourism Education, 1 (1), 19-28.

Slattery, P. (2003). Finding the hospitality industry (Slattery's reply to Brotherton), Journal of Hospitality, Leisure, Sport and Tourism Education, 2(1), 120-121.

Stear, L. \& Griffin, T. (1993). Demythologizing the nexus between tourism and hospitality: 
Implications for education. Tourism Management, 14(1), 41-51.

Stevens, B. (2001). Hospitality ethics: Responses from human resource directors and students to seven ethical scenarios. Journal of Business Ethics, 30(3), 233-242.

Taylor, S. \& Edgar, D. (1996). Hospitality research: The emperor's new clothes. International Journal of Hospitality Research, 15(3), 211-227.

Taylor, S. \& Edgar, D. (1999). Lacuna or lost cause? Some reflections on hospitality management research. In B. Brotherton (Ed) The handbook of contemporary hospitality management research (pp. 19-38). New York: Wiley.

Thomas, R. \& Harris, V. (2001). Exploring connections between teaching and research in hospitality management. International Journal of Hospitality Management., 20 (3), 245-257.

Thompson, P. (2004) Brands, boundaries and bandwagons: A critical reflection on critical management studies. In S. Fleetwood and S. Ackroyd (Eds.) Critical realist applications in organisation and management studies (pp.51-66). London: Routledge.

Tribe, J. (2002). The philosophic practitioner. Annals of Tourism Research, 29(2), 338357.

Tribe, J. (2006). The truth about tourism. Annals of Tourism Research, 33(2), 360-81. Upchurch, R. (1998). A conceptual foundation for ethical decision making:

A stakeholder perspective in the lodging industry (U.S.A). Journal of Business Ethics, 17 (12), 1349-1361.

Wilson, E., Harris, C. \& Small, J. (2008). Furthering critical approaches in tourism and hospitality studies: Perspectives from Australia and New Zealand. Journal of Hospitality and Tourism Management, 15, 15-18.

Wood, R. C. (1983). Theory, management and hospitality: A response to Nailon. International Journal of Hospitality Management, 2(2), 103-4.

Wood, R. C. (1988). Against social science? International Journal of Hospitality Management , 7(3), 239-250.

Wood, R. C. (1999). Traditional and alternative research philosophies. In B. Brotherton (Ed) The handbook of contemporary hospitality management research (pp. 3-18). New York: Wiley.

Wood, R. (2007). The future of food and beverage management research. Journal of Hospitality \& Tourism Management, 14(1), 6-16. 